\title{
БИГДАТА В АСПЕКТЕ ПРОТИВОДЕЙСТВИЯ КОРРУПЦИИ НА ГОСУДАРСТВЕННОЙ СЛУЖБЕ
}

\author{
Сафонова Наталья Алексеевна \\ Старший преподаватель, Национальный \\ исследовательский университет «Московский \\ государственный технический университет \\ им. Н.Э. Баумана» \\ safonova-natalya-2014@mail.ru
}

BIGDATE IN THE ASPECT OF ANTI-CORRUPTION IN THE PUBLIC SERVICE

\section{N. Safonova}

Summary. The article describes the concept of "BigData" ("Big Data", "BigData"), presents the possibilities of using technology in the civil service to analyze the data array obtained during the registration of declarations on property, income and expenses of civil servants and their family members. The positive values of the implementation of BigData technologies in public administration are described for the analysis and taking of preventive measures in the event of corruption risks being identified. Also noted are the problematic aspects associated with the collection, storage, algorithms for analyzing Big Data.

Keywords: anti-corruption, digital technologies, Big Data, BigData, BigData, public service, digitalization. и нформационно-ориентированные

технологии, получившие бурное развитие и внедрение во все сферы экономических, общественных, государственных правоотношений в начале 21 века, позволили накапливать множество данных, не всегда связанных между собой и структурированных. Вместе с тем, информация как нематериальный ресурс является реально возможной силой для получения закономерностей развития и функционирования каких-либо процессов, имеющих непосредственную и общезначимую позицию для частных, коллективных, межгосударственных, международных отношений.

Установление коррупции как негативного социального и правового явления на международном уровне, отраженное в 2003 году путем принятия Конвенции ООН против коррупции, консолидировало усилия государств-участников в принятии и укреплении мер, направленных на более эффективное и действенное предупреждение коррупции и борьбу с ней, в поощрении и укреплении международного сотрудничества и технической помощи в предупреждении и борьбе с коррупцией, в поощрении честности, неподкупности, ответственности, в надлежащем управлении публичными делами и публичным имуществом.

Российская Федерация и до 2003 года осуществляла мероприятия по противодействию коррупции, в некоторых областях такие действия осуществлялись регулярно.

Однако принятие отдельного национального нормативно-правового документа в 2008 году: Федерального закона «О противодействии коррупции» - позволило оформить институт противодействия коррупции как комплексный институт, возлагающий консолидацию и координацию общих усилий на различных субъектов социальной, политической, управленческой сферы: федеральных органов государственной власти, органов государственной власти субъектов Российской Федерации, органов местного самоуправления, институтов гражданского общества, организаций и физических лиц в пределах их полномочий.

Современное законодательное регулирование института декларирования имущества, доходов и рас- 
ходов государственными служащими и некоторыми членами их семей основано на следующих основополагающих нормативно-правовых актов в этой области:

- Федеральный закон от 27.07.2004 г. № 79-Ф3 «О государственной гражданской службе Российской Федерации»;

- Федеральный закон от 25 декабря 2008 г. № 273Ф3 «О противодействии коррупции»

- Указ Президента РФ от 18.05.2009 г. № 557 «Об утверждении перечня должностей федеральной государственной службы, при замещении которых федеральные государственные служащие обязаны представлять сведения о своих доходах, об имуществе и обязательствах имущественного характера, а также сведения о доходах, об имуществе и обязательствах имущественного характера своих супруги (супруга) и несовершеннолетних детей.

- Федеральный закон от 03.12.2012 г. № 230-Ф3 «О контроле за соответствием расходов лиц, замещающих государственные должности, и иных лиц их доходам».

Следует отметить, что существенные усилия по противодействию коррупции реализуются в первую очередь среди государственных служащих, как непосредственно выполняющих государственные функции и наделенные властными полномочиями. Комплекс мероприятий, предусмотренных для указанной категории лиц, предусматривает следующие обязанности и запреты, обусловленные правовым статусом:

- представление сведений в виде декларации об имуществе

- запрет на хранение денег в иностранных банках

- подача декларации об имуществе, доходах и расходах в отношении себя, супруги (супруга) и несовершеннолетних детей.

Федеральным законом «О противодействии коррупции» предусмотрено, что что проверка достоверности, полноты сведений о доходах осуществляется в порядке, установленном законом о противодействии коррупции и иными нормативными правовыми актами РФ. Единого органа по анализу представляемых деклараций не существует. Проверками деклараций занимаются Прокуратура РФ, Федеральная налоговая служба, Совет по противодействию коррупции при Президенте Российской Федерации, комиссии по соблюдению требований к служебному поведению государственных служащих и урегулированию конфликта интересов в каждом ведомстве.

Современным научно-техническим достижением, имеющим инструментарий для проведения необходимого анализа и обобщения, выявления связей, законо- мерностей, является «БигДата» (Big Data, Большие данные).

Термин, впервые использованный редактором журнала Nature Клиффордомм Линчем в спецвыпуске 2008 года [1] в контексте взрывного роста объемов информации в мире, а в последствии и получивший международное признание, в современный период может быть активно использован для целей совершенствования института противодействия коррупции.

БигДата - это различные инструменты, подходы и методы обработки как структурированных, так и неструктурированных данных для того, чтобы их использовать для конкретных задач и целей. При этом отличие структурированных от неструктурированных данных состоит в организации информации в особом порядке.

Сегодня данные содержатся во всем: в смартфонах, телевизионном оборудовании, стиральной машине, светофоре, лекарственных препаратах, водительском удостоверении, в персонифицированном виртуальном личном кабинете. Современный инструментарий БигДата позволяет соотнести разрозненные источники информации для принятия автоматических решений на основе полученных аналитических выводов.

Со стороны государства наблюдается повышенный интерес к новым технологиям, возможностям обработки и анализа цифровой информации, тем более что цифровые данные повсеместно используются для целей государственной службы. Например, Федеральная таможенная служба РФ реализует масштабный проект по цифровизации таможенного администрирования [2]. Владимир Булавин отметил, что электронные технологии сегодня являются неотъемлемой частью внутренних процессов таможенных органов. Стратегия развития таможенной службы до 2030 года в качестве принципов содержит указание на оптимизацию и совершенствование таможенного администрирования; автоматизацию и информатизацию сквозных бизнес-процессов деятельности таможенной службы на основе передовых технологий; клиентоориентированность и бесконтактность [3].

В научных исследованиях отмечается, что залогом эффективности государственной антикоррупционной политики является комплексный подход к решению данной задачи, предполагающий одновременную проработку проблемных вопросов противодействия коррупции на всех направлениях: от совершенствования законодательства до повышения уровня правового сознания [4].

При поиске причин коррупции и способов противодействия ей учитываются современные достижения 
не только в области совершенствования законодательства [5], но и информационно-технические возможности по сбору, хранению, фиксации, анализу совершаемых действий и имеющихся сведений об участниках правоотношений [6], [7], [8], [9].

БигДата можно описать через призму пяти элементов: объем, высокая скорость изменения данных, разнообразие, достоверность и ценность. Их особенностью является свойство экспоненциального роста, когда возрастание величины происходит пропорционально значению самой величины. Скорость характеризует развитие данных в динамике, данные постоянно прирастают, именно поэтому и требуется их быстрая обработка для получения результатов.

Преимуществами Больших Данных называются: выявление скрытых закономерностей, прогнозирование поведения людей, техники, природы, создание цифрового портрета гражданина, выявление причинно-следственных связей.

Для государственной службы анализ собранных материалов предполагает как можно более экономичные способы обработки данных, поэтому основное внимание должно быть уделено инновационным способам получения выводов и аналитики данных.

Объем информации, накопленный по декларациям государственных служащих и членов их семей с 2004 года, а в отношении некоторых сведений даже ранее, однозначно требует внимания не только правоохранительных органов при осуществлении обязанностей проверки полноты и достоверности представленных сведений, но и реализации возможностей анализа поступаемых сведений для выявления причин коррупции, наиболее подверженных коррупционным рискам должности/ структурные подразделения / государственные органы. То есть необходимо использовать накопленную информацию не только для выявления противоправных действий с коррупционным компонентом, но и для отображения рисков коррупционных проявлений, конфликтов интересов, предикторов коррупции.

При этом актуальным вопросом является постановка задач для аналитического процесса и получение данных, отвечающих этим задачам.

Идеи применения передовых цифровых технологий реализуются и иностранными государствами. Так, например, отмечается, что в странах с высокоразвитой экономикой новые цифровые технологии широко применяются в таможенном деле. Например, в Великобритании, Южной Корее, Китайской Народной Республике,
Канаде и Сингапуре успешно разрабатываются и реализуются такие цифровые технологии, как «большие данные» (Big Data) и «искусственный интеллект» (artificial intelligence). В Австралии планируется применение цифровой идентификации товаров, в качестве которой будет выступать радиочастотная идентификация (radiofrequency identifcation - RFID) [10].

Преимущества Больших Данных в области противодействия коррупции на государственной службе очевидны. Анализ массива данных на основе деклараций о доходах и расходах позволяет увидеть закономерности, которые незаметны при анализе данных человеком. Также проведение аналитических действий в реальном времени позволяет увеличить скорость принятия решений по конкретной выявленной проблеме, не затрачивая временные ресурсы.

Аналитическая работа, производимая с помощью современных алгоритмов БигДата, на основе представленных за отчетный период деклараций о доходах и расходах, позволит выявить потенциальные риски системной коррупционной деятельности в реальном времени, получить результат и произвести автоматизированный учет разнообразных параметров коррупционных проявление, таких как: конфликт интересов, коррупционные риски, статистические сведения, привязанные к конкретному государственному служащему, его выполняемой должностной функции [6].

В некоторых случаях анализ фрагментарных данных имеет существенный потенциал. Например, структура таможенных органов в силу выполняемых ими функций обширна. При этом декларацию о доходах, расходах, имуществе и обязательствах имущественного характера Федеральной таможенной службы подают три группы сотрудников: руководящий состав ФТС и члены их семей (8 сотрудников); должностные лица ФТС и члены их семей (23 сотрудника); работники организаций, созданных для выполнения задач, стоящих перед ФТС, и члены их семей (44 сотрудников). Шереметьевская таможня публикует сведения о доходах, расходах, имуществе и обязательствах имущественного характера в отношении 137 сотрудника, Брянская таможня в отношении 161 сотрудника, Владивостокская таможня - в отношении 143 сотрудника и так далее [11]. Если учесть, что каждый сотрудник предоставляет аналогичную декларацию по супругу (супруге) и несовершеннолетним детям - то объем предоставляемой информации впечатляет. Естественно, что, проводя анализ представленных данных в рамках одного структурного подразделения, невозможно увидеть закономерности или предпосылки конфликта интересов из-за используемых алгоритмов изучения. Вместе с тем, применение концепции Больших Данных при структурировании, 
вычленению и анализе представленной в декларациях информации - это прогрессивное получение полезных сведений, позволяющих не только выявить коррупционные правонарушения, но и выделить проблемные узлы, влекущие коррупционные риски, принять необходимые превентивные меры для предотвращения формирования коррупционных связей.

Следует отметить, что БигДата - это сложные и объемные массивы информации, представленные зачастую в неупорядоченном виде, для получения необходимых сведений требующие предварительной обработки путем использования информационно-компьютерного моделирования. Фрагментарные данные, пропущенные через аналитическую систему, приобретают упорядоченную структуру, отсеиваются неинформативные части.

Потенциальная эффективность подхода к анализу информации, содержащейся в имущественных декларациях государственных служащих, оценивается автором как высокая. Вместе с тем, очевидна проблематика, которую следует выделить при указании на положительные черты.

Во-первых, это четкое законодательное закрепление использования технологии Больших Данных по отношению к декларациям государственных служащих. В настоящее время развитие информационно-компьютерных технологий опережает нормативно-правое регулирование, что влечет правовые пробелы, сложности интерпретации совершаемых действий в силу обобщенности описания терминов, фрагментарность правового регулирования. Системообразующими нормативно-правовыми актами в этой сфере являются Федеральный закон «О защите персональных данных» от 27 июля 2006 г. № 152-Ф3 и Федеральный закон от 27 июля 2006 г. № 149-Ф3 «Об информации, информационных технологиях и о защите информации». Программа «Цифровая экономика» называет Большие Данные прорывными цифровыми технологиями [12]. Нормативное регулирование БигДата является важнейшим направлением развития внедрения и использования технологий. Приказом Росстандарта утверждён ГОСТ Р ИСО/МЭК 20546-2021 «Информационные тех- нологии. Большие данные. Обзор и словарь» -терминологический стандарт, ставший первым отечественным нормативно-техническим документом в сфере больших данных (Big data) [13].

Во-вторых, для обработки больших объемов данных требуются специальные технологии хранения, упорядочивания, анализа такой информации, обеспечение защиты и сохранности, которые опираются на фундаментальные знания математических дисциплин и информатики для проектирования инструментария и статистического анализа. Привлечение специалистов - одно из условий успешного освоения технологий Биг Дата на государственной службе.

В-третьих, привлечение дополнительного финансирования и оптимизация расходов. Большие Данные это дорогостоящие технологии, требующие серьезных финансовых затрат. Для государственного сектора привлечение дополнительных средств должно быть обоснованно, просчитано и экономически целесообразно.

В-четвертых, аналитические подходы к использованию Больших Данных предполагают наличие не просто массива данных, а грамотное построение задач и поиск необходимых данных для их решения.

Таким образом, потенциал Больших Данных на государственной службе следует реализовывать последовательно, с учетом исполнения государственной программы «Цифровая экономика», утвержденная Правительством РФ в 2017 году, поскольку преобразование в цифровую систему в первую очередь связано с управлением Большими Данными. Объединение информации по декларациям государственных служащих всех государственных органов и структурных подразделений в единую инфраструктуру создает основу для использования технологий Интернета Вещей, когда через виртуальные следы, запросы поисковиков, фиксации совершаемых действий при выполнении должностных полномочий создается возможность выявления коррупционных рисков, ситуаций конфликта интересов, осуществления превентивных мероприятий по предотвращению коррупционных ситуаций.

\section{ЛИТЕРАТУРА}

1. Volume 455 Issue 7209,4 September 2008 / URL: https://www.nature.com/nature/volumes/455/issues/7209 (дата 0бращения 08.07.2021)

2. МФФ-2019: В работу таможни планируется внедрить методы искусственного интеллекта и обработки больших массивов данных / URL: https://customs. gov.ru/press/federal/document/205873 (дата обращения: 08.07.2021)

3. Распоряжение Правительства РФ от 23.05.2020 № 1388-р «Стратегия развития таможенной службы Российской Федерации до 2030 года» / URL: http:// www.consultant.ru/document/cons_doc_LAW_353557/ (дата обращения: 08.07.2021)

4. Черепанова Е.В. Противодействие коррупции в государственном управлении // Журнал российского права. 2017. №4 (244). С. 100-105 
5. Сафонова Н.А. Основные направления профилактики латентности коррупционных правонарушений в таможенных органах // Международный научно-исследовательский журнал. 2020, № 5-2 (95), с. 142-146

6. Кравченко А.Г., Овчинников А.И., Мамычев А.Ю., Воронцов С.А. Использование цифровых технологий в сфере противодействия коррупции // Административное и муниципальное право, 2020, № 6, с. 52-63.

7. Сафонова Н.А. Использование современных технологий в противодействии коррупции в таможенных органах // Ломоносовские чтения - 2020: Материалы ежегодной научной конференции МГУ, Севастополь / под ред. 0.А. Шпырко - Севастополь: филиал Московского государственного университета им. М.В. Ломоносова в г. Севастополе, 2020, с. 82-83.

8. Сафонова Н.А. Возможности блокчейн-технологий в сфере противодействия коррупции // Будущее машиностроения России: сборник докладов: В 2 томах, Москва, 22-25 сентября 2020 года / Союз машинострителей России, Московский государственный технический университет имени Н.Э. Баумана (национальный исследовательский университет). Москва: Издательство МГтУ им. Н.Э. Баумана, 2020, с. 393-395.

9. Сафонова Н.А. Цифровизация в развитии антикоррупционных мер (на примере таможенных органов) // Глобальная экономика в XXI веке: роль биотехнологий и цифровых технологий: сборник научных статей по итогам работы шестого круглого стола с международным участием. Москва, 15-16 августа 2020 года. Москва: О6щество с ограниченной ответственностью «Конверт», 2020, с. 163-165.

10. Сомов Ю.И., Шашаев А.Е. Возможности применения новых цифровых технологий в таможенном деле // Вестник Российской таможенной академии. 2020. № 1. С. $29-41$

11. Сведения 0 доходах, расходах, 06 имуществе и обязательствах имущественного характера должностных лиц Федеральной таможенной службы и членов их семей с 1 января 2020 года по 31 декабря 2020 года / URL: https://customs.gov.ru/activity/protivodejstvie-korrupczii/cvedeniya-0-doxodax,rasxodax,-ob-imushhestve-i-obyazatel-stvax-imushhestvennogo-xaraktera-dolzhnostnyx-licz-federal-noj-tamozhennoj-sluzhby-i-chlenov-ix-semej/ document/285998 (дата обращения 08.07.2021)

12. Распоряжение Правительства РФ от 28.07.2017 № 1632-р «06 утверждении программы «Цифровая экономика Российской Федерации»» (утратил силу) / URL: http://www.consultant.ru/document/cons_doc_LAW_221756/ (дата 0бращения 10.07.2021)

13. Утвержден первый национальный стандарт в области больших данных // URL: https://www.rst.gov.ru/portal/gost/home/presscenter/news?portal: componentld=88beae40-0e16-414c-b176-d0ab5de82e16\&navigationalstate=JBPNS_r00ABXczAAZhY3Rpb24AAAABAA5zaW5nbGV0ZXdzVmlldwACaWQA AAABAAQ4MjgyAAdfXOVPRI9f (дата обращения 18.07.2021)

14. Соснин К.А. Правовое регулирование Больших данных: зарубежный и отечественный опыт // Журнал Суда по интеллектуальным правам, 2019, № 25, c. $30-42$

(c) Сафонова Наталья Алексеевна ( safonova-natalya-2014@mail.ru ).

Журнал «Современная наука: актуальные проблемы теории и практики» 